\title{
Auf der Suche nach brauchbaren Serumalternativen
}

\author{
GERHARD GSTRAUNTHALER ${ }^{1}$, TONI LINDL ${ }^{2}$ \\ ${ }^{1}$ SEKTION FÜR PHYSIOLOGIE, MEDIZINISCHE UNIVERSITÄT INNSBRUCK, ÖSTERREICH \\ ${ }^{2}$ INSTITUT FÜR ANGEWANDTE ZELLKULTUR, MÜNCHEN
}

\section{Fetal bovine serum (FBS) provides essential components for growth and proliferation of cells in vitro, like hormones and growth factors, attach- ment and spreading factors and transport proteins. However, the use of FBS bears a number of disadvantages, and serious scientific and ethical concerns were raised regarding its harvest and production. For decades, big efforts were made in the search for valuable alternatives to FBS. Most recently, we were able to offer a promising solution.}

DOI: $10.1007 / \mathrm{s} 12268-017-0843-\mathrm{Z}$

(C) Der Autor 2017. Dieser Artikel ist eine Open-Access-Publikation

Die Verwendung von Seren als Zusatz zu Kulturmedien ist weltweite Routine in der Zell- und Gewebekultur. Seren, vor allem fetales Kälberserum (FBS), versorgen die Kulturen mit Hormonen, Wachstums- und Anheftungsfaktoren, Bindungs- und Transportproteinen, zusätzlichen Aminosäuren, Vitaminen, anorganischen Salzen, Spurenelementen sowie Puffer- und Neutralisationssyste-

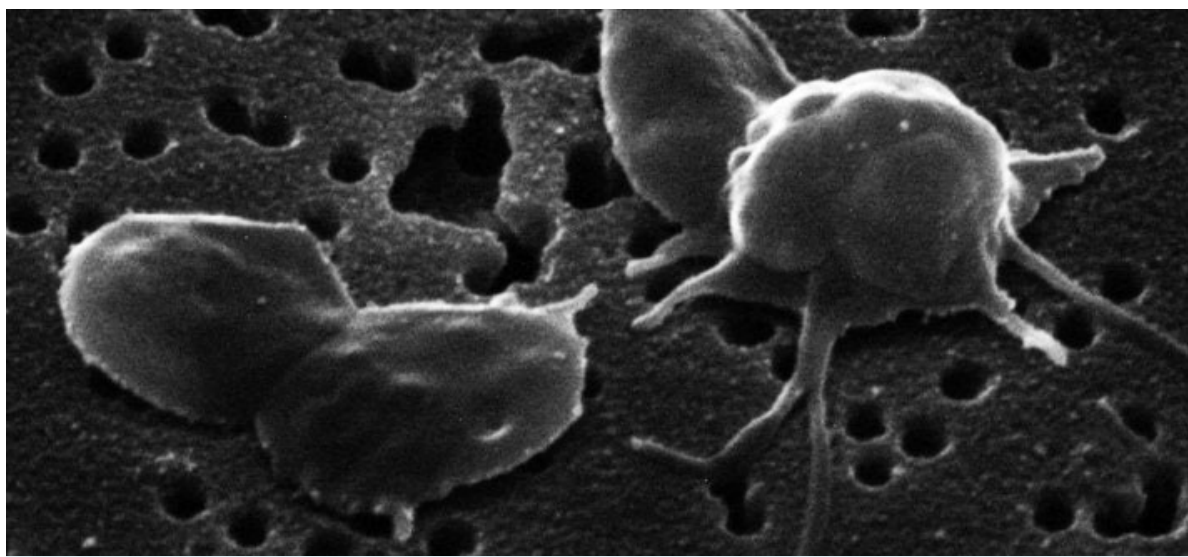

$\Delta$ Abb. 1: Rasterelektronenmikroskopische Aufnahme ruhender (links) und aktivierter (rechts) Thrombozyten auf einem Sterilfilter (Millipore, Porengröße: 0,22 $\mu \mathrm{m}$ ). Wenn Blutplättchen aktiviert werden, durchlaufen sie charakteristische, morphologische Veränderungen und bilden lange Pseudopodien, mit denen sie an den Wundrändern haften. Gleichzeitig werden durch Exozytose die $\alpha$-Granula und die elektronendichten Granula entleert. Neben der Freisetzung von Serotonin aus den elektronendichten Granula zur Gefäßverengung (Vasokonstriktion) erfolgt die Ausschüttung $\alpha$-granulärer Faktoren zur Initiierung und Aufrechterhaltung der Gerinnungskaskade und von Wachstumsfaktoren für die nachfolgende Wundheilung. oder Prionen enthalten [1, 3, 4]. Darüber hinaus finden sich enorme jahreszeitliche und geografische Schwankungen in der qualitativen und quantitativen Zusammensetzung einzelner Serumchargen, weshalb oft aufwendige Chargenprüfungen vorgenommen werden müssen. Mit dem Serum wird somit ein undefiniertes Gemisch biologisch aktiver Substanzen in ein definiertes Kulturmedium eingebracht.

Fetales Kälberserum ist ein Nebenprodukt der Rindfleischindustrie. Dadurch ist der Serummarkt von vielen äußeren Faktoren abhängig. Es wird deshalb auch immer öfter die Frage aufgeworfen, ob der weltweite Bedarf an fetalem Kälberserum in Forschung und Biotechindustrie überhaupt abgedeckt werden kann. Kürzlich publik gewordene Skandale um gepanschtes Kälberserum verstärken noch die Bedenken um Reinheit und Qualität der Seren [5].

Der gravierendste Nachteil ist allerdings die Methode der Serumgewinnung. Fetales Kälberserum wird von Feten trächtiger Kühe gewonnen. Es wird angenommen, dass weltweit jährlich ca. 800.000 Liter fetales Kälberserum benötigt werden, was rund zwei Millionen Rinderfeten entspricht. In den letzten Jahren sind die ethischen Bedenken gegenüber der Serumgewinnung immer lauter geworden, und es wurde eine Reihe von Alternativen aufgezeigt, um durch eine Verringerung im Verbrauch (reduction) bzw. durch den vollständigen Ersatz (replacement) von fetalem Kälberserum im Sinne des 3-RPrinzips (reduction, replacement, refinement) die jährlichen Verbrauchszahlen an Rinderfeten zu senken [3, 4].

Trotz vieler innovativer Ansätze und der Entwicklung serumfreier Medien für eine Vielzahl von Zellen ist und bleibt die Zugabe von fetalem Kälberserum immer noch das Mittel der Wahl in der Zellkultur.

Um diese Nachteile der Verwendung von Serum zu vermeiden und um definierte und kontrollierte Kulturbedingungen zu schaffen, wurde in den letzten Jahren intensiv nach Alternativen zur Verwendung von Serum in 
der Zellkultur gesucht. Nunmehr zeichnet sich eine vielversprechende Lösung ab [6-8].

\section{Thrombozytenlysate als Alternative zum fetalen Kälberserum (FBS)}

Die neueste Entwicklung sind Lysate humaner Thrombozytenkonzentrate, die mit thrombozytären Wachstumsfaktoren hoch angereichert sind. Serum enthält eine Vielzahl mitogener Wachstumsfaktoren, die im Rahmen des Gerinnungsprozesses aus aktivierten Thrombozyten freigesetzt werden. Viele dieser Faktoren wurden schon früh als essenzielle Mitogene in serumfreien Kulturmedien identifiziert [2]. Aus dieser Überlegung heraus wurden in den letzten Jahren Lysate humaner Thrombozyten als vollwertiger Ersatz für fetales Kälberserum in einer Vielzahl unterschiedlicher Kultursysteme etabliert. Ausgangsprodukt sind abgelaufene Thrombozytenspenden aus Blutbanken. Spenderthrombozyten haben eine Lebensdauer von nur fünf Tagen, innerhalb derer sie klinisch verwendet werden dürfen. Dadurch fallen immer wieder Spenderthrombozytenkonzentrate an.

Die Anwendung von Thrombozytenlysaten in der Zellkultur ist vor dem Hintergrund der Physiologie der Thrombozyten zu sehen. Thrombozyten (Blutplättchen) produzieren eine Reihe von Wachstumsfaktoren, die sie in ihren $\alpha$-Granula speichern und nach Aktivierung freisetzen (Abb. 1). Diese Faktoren spielen eine entscheidende Rolle bei der Blutstillung und der daran anschließenden Wundheilung. Ruhende Thrombozyten sind ein bis zwei Mikrometer große Scheibchen (Blutplättchen) mit glatter Oberfläche. Diese kernlosen Scheibchen besitzen allerdings noch Mitochondrien, Lysosomen und Peroxysomen sowie Speichergranula, die in $\alpha$-Granula und elektronendichte Granula (dense granula) unterteilt werden. Die in diesen Granula gespeicherten Inhaltsstoffe können nach funktionellen Kategorien geordnet werden: in vasokonstriktorische Faktoren (Serotonin, plateletderived growth factor [PDGF]), aggregationsfördernde Faktoren (ADP, Thrombospondin, Fibrinogen), adhäsionsfördernde Faktoren (Fibronektin, Von-Willebrand-Faktor) und wachstumsfördernde Faktoren (PDGF, epithelial growth factor [EGF], transforming growth factor- $\beta$ [TGF- $\beta]$, fibroblast growth factor [FGF], vascular endothelial growth factor [VEGF]).

Bekanntlich ist der bei der Rohserumgewinnung ablaufende Gerinnungsprozess von entscheidender Bedeutung für die Qualität des Serums. Es kann demnach davon ausge- gangen werden, dass die im Serum nachgewiesenen und für die Proliferation kultivierter Zellen essenziellen Faktoren, wie EGF, PDGF, FGF, TGF- $\beta$, VEGF und andere, thrombozytären Ursprungs sind. Der hohe Gehalt an spezifischen Wachstumsfaktoren macht damit Lysate humaner Thrombozyten zu einem hervorragenden, wenn auch nicht vollständig definierten, Ersatzprodukt für die Zellund Gewebekultur [6].

Wie oben ausgeführt, dienen als Ausgangsmaterial abgelaufene Thrombozytenkonzentrate, welche durch Apherese gewonnen wurden. Thrombapheresen werden in zertifizierten Blutbanken durchgeführt. Damit steht ein nach Ablauf der Verwendungsdauer nach europäischen Richtlinien hergestelltes, für den therapeutischen Einsatz (Thrombozytenspende) zertifiziertes und qualitätsgetestetes Ausgangsprodukt zur Verfügung. Die Spenderthrombozyten werden gewaschen, in einer Salzlösung resuspendiert und in einem einfachen Gefrier-Auftau-Verfahren lysiert. Die Lysate können als Serumersatz zu Basalmedien, wie MEM, DMEM, DMEM/Ham's F-12 oder RPMI-1640 in einer Konzentration von fünf Prozent (v/v) zugegeben werden.

Darüber hinaus steht mit humanen Thrombozytenlysaten ein Kultursystem rein auf Basis humaner Faktoren zur Verfügung. Solche Systeme, frei von jeglichen Komponenten tierischen Ursprungs (animal-derived component-free) eignen sich besonders für die Stammzellkultur und im Tissue Engineering [7-11].

\section{Zusammenfassung}

Fetales Kälberserum kann nicht selbst gewonnen bzw. hergestellt werden. Die mögliche Verfügbarkeit von abgelaufenen Spenderthrombozytenkonzentraten aus Blutbanken jedoch und die Einfachheit der Lysatherstellung geben Anlass zur Hoffnung, dass dieser innovative Ansatz eines Serumersatzes schon bald vermehrt Einzug in die Zellkulturlabors finden wird [6-8].

\section{Danksagung}

Für die finanzielle Unterstützung unserer wissenschaftlichen Arbeiten zur Entwicklung der Plättchenlysate sei der Stiftung ProCare, Zürich, und der Stiftung SET, Frankfurt a. M., herzlich gedankt.

\section{Literatur}

[1] Gstraunthaler G, Lindl T (2013) Zell- und Gewebekultur. Allgemeine Grundlagen und spezielle Anwendungen. 7. Aufl. Springer-Spektrum, Heidelberg
[2] Gstraunthaler G (2003) Alternatives to the use of fetal bovine serum: serum-free cell culture. ALTEX 20:275-281 [3] Brunner D, Frank J, Appl H et al. (2010) Serum-free cell culture: the serum-free media interactive online database. ALTEX 27:53-62

[4] van der Valk J, Brunner D, De Smet K et al. (2010) Optimization of chemically defined cell culture media replacing fetal bovine serum in mammalian in vitro methods. Toxicol In Vitro 24:1053-1063

[5] Gstraunthaler G, Lindl T, van der Valk J (2014) A severe case of fraudulent blending of fetal bovine serum strengthens the case for serum-free cell and tissue culture applications. Altern Lab Anim 42:207-209

[6] Rauch C, Feifel E, Amann E-M et al. (2011) Alternatives to the use of fetal bovine serum: human platelet lysates as a

serum substitute in cell culture media. ALTEX 28:305-316 [7] Gstraunthaler G, Rauch C, Feifel E et al. (2015) Preparation of platelet lysates for mesenchymal stem cell culture media. J Stem Cells Rev Rep 2:1021

[8] Burnouf T, Strunk D, Koh MBC et al. (2016) Human platelet lysate: replacing fetal bovine serum as a gold standard for human cell propagation? Biomaterials 76:371-387 [9] Bieback K (2013) Platelet lysate as replacement for fetal bovine serum in mesenchymal stromal cell cultures. Transfus Med Hemother 40:326-335

[10] Hemeda H, Giebel B, Wagner W (2014) Evaluation of human platelet lysate versus fetal bovine serum for culture of mesenchymal stromal cells. Cytotherapy 16:170-180

[11] Shih DT, Burnouf T (2015) Preparation, quality criteria, and properties of human blood platelet lysate supplements for ex vivo stem cell expansion. New Biotechnol 32:199-211

\section{Open Access.}

Dieser Artikel wird unter der Creative Commons Namensnennung 4.0 International Lizenz (http://creativecommons.org/licenses/ by/4.0/deed.de) veröffentlicht, welche die Nutzung, Vervielfältigung, Bearbeitung, Verbreitung und Wiedergabe in jeglichem Medium und Format erlaubt, sofern Sie den/die ursprünglichen Autor(en) und die Quelle ordnungsgemäß nennen, einen Link zur Creative Commons Lizenz beifügen und angeben, ob Änderungen vorgenommen wurden.

Open access funding provided by Medical University of Innsbruck, Austria.

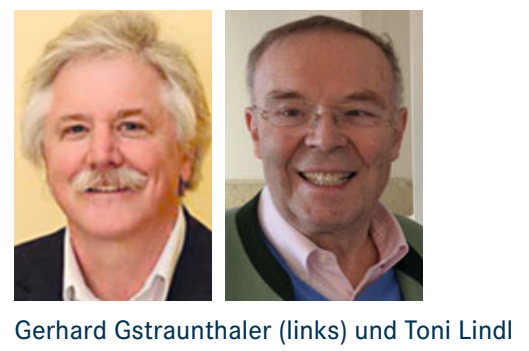

Korrespondenzadresse:

Prof. Dr. Gerhard Gstraunthaler

Sektion für Physiologie

Medizinische Universität Innsbruck

Schöpfstraße 41

A-6020 Innsbruck

Tel.: +43-(0)512-9003-70810

Fax: +43-(0)512-9003-73800

gerhard.gstraunthaler@gmail.com

https://www.i-med.ac.at/dpmp/physiologie/

research/gstraunthaler/ 